OPEN ACCESS

Edited by:

Owen McCarty,

Oregon Health \& Science

University, United States

Reviewed by:

Biana Godin,

Houston Methodist

Research Institute,

United States

Monica M. Burdick,

Ohio University, United States

*Correspondence:

Bryan C. Fuchs

bfuchs@partners.org

Zdravka Medarova

zmedarova@partners.org

Specialty section: This article was submitted to Cancer Molecular Targets and Therapeutics,

a section of the journal

Frontiers in Oncology

Received: 11 May 2018 Accepted: 22 June 2018 Published: 10 July 2018

Citation:

Yoo B, Fuchs BC and Medarova Z

(2018) New Directions in the

Study and Treatment of

Metastatic Cancer.

Front. Oncol. 8:258.

doi: 10.3389/fonc.2018.00258

\section{New Directions in the Study and Treatment of Metastatic Cancer}

\author{
Byunghee Yoo ${ }^{1}$, Bryan C. Fuchs ${ }^{2 *}$ and Zdravka Medarova ${ }^{1 *}$ \\ ${ }^{1}$ MGH/MIT/HMS Athinoula A. Martinos Center for Biomedical Imaging, Massachusetts General Hospital, Harvard \\ Medical School, Boston, MA, United States, ${ }^{2}$ Division of Surgical Oncology, Massachusetts General Hospital Cancer \\ Center and Harvard Medical School, Boston, MA, United States
}

Traditional cancer therapy has relied on a strictly cytotoxic approach that views non-metastatic and metastatic tumor cells as identical in terms of molecular biology and sensitivity to therapeutic intervention. Mounting evidence suggests that, in fact, non-metastatic and metastatic tumor cells differ in key characteristics that could explain the capacity of the metastatic cells to not only escape the primary organ but also to survive while in the circulation and to colonize a distant organ. Here, we lay out a framework for a new multi-pronged therapeutic approach. This approach involves modifying the local microenvironment of the primary tumor to inhibit the formation and release of metastatic cells; normalizing the microenvironment of the metastatic organ to limit the capacity of metastatic tumor cells to invade and colonize the organ; remediating the immune response to tumor neoantigens; and targeting metastatic tumor cells on a systemic level by restoring critical and unique aspects of the cell's phenotype, such as anchorage dependence. Given the limited progress against metastatic cancer using traditional therapeutic strategies, the outlined paradigm could provide a more rational alternative to patients with metastatic cancer.

Keywords: metastasis, cancer stabilization, cancer microenvironment, cancer therapy, targeted therapy

\section{METASTATIC CANCER AS A UNIQUE THERAPEUTIC CHALLENGE}

The traditional view of tumors has been as homogeneous masses of cells that proliferate uncontrollably and are resistant to pro-apoptotic stimuli. Now, we know that this view is overly simplistic. In fact, tumors are highly heterogeneous assemblies of cells that participate in constant interplay between themselves and a dynamic local microenvironment, continually changing and adapting in the process. The most insidious of these cells are those that acquire the capability to break out of the primary tumor mass, travel through the circulation, and colonize a new vital organ in the process of metastasis. Importantly, these cells are genetically and phenotypically distinct from the majority of the cells in the tumor mass, spawning metastatic lesions that have diverged significantly in their gene expression profile from their respective primary tumors.

Based on this knowledge, it becomes clear that successful cancer therapy has to include a component that specifically targets the metastatic niche. The metastatic niche presents a distinct challenge in terms of molecular biology, local tissue microenvironment, immunological profile, and physicochemical tissue properties that are keys to the success of therapy. This is particularly well established with regard to breast cancer. Numerous studies of the receptor status of patientmatched primary and metastatic tumors have reported high discordance rates. In addition, while gene expression profiling has suggested mostly concordance between primary tumors and lymph node/distant metastases, a small number of genes that differ have also been identified, with a large 
number of the differences being at the non-coding RNA and epigenetic level. Whole-genome sequencing comparisons have also been performed in individual patients and have found heterogeneity in primary tumors and significant differences in the corresponding metastases. A very comprehensive meta-analysis of this evidence can be found in Kroigard et al. (1). Overall, the majority of the studies reveal therapeutically meaningful discordances between primary tumors and metastases, underscoring the need for analysis of metastatic tissue as a guide to therapy.

The traditional focus on the primary tumor for the development of cancer therapies is partly behind the poor outcomes in cancer patients diagnosed with metastatic disease. Conventional therapies targeted toward the primary tumor cell oftentimes do not affect the metastatic cell and, in fact, may promote metastasis. Such is the case for paclitaxel, cisplatin, anti-androgens, everolimus, and sunitinib. This fact is behind the poor outcomes in patients diagnosed with metastatic disease despite the good prognosis of patients with localized cancer of the same organ of origin (2). It is not surprising that 9 out of 10 deaths from cancer are, in fact, due to metastasis.

\section{CANCER "STABILIZATION" THERAPY AS AN ALTERNATIVE THERAPEUTIC PARADIGM}

Toward the goal of developing metastases-specific therapies, an important question that needs to be addressed is, what makes a cell capable of leaving the organ of its origin, surviving in the circulation and in its non-native tissue, and even colonizing this tissue, which has immunological, physicochemical, and molecular, genetic, and epigenetic properties distinct from the native organ in which the cell originated. In this sense, metastasis can be seen as a disease of tissue-to-tissue histocompatibility. The hypothesis that we propose is that cells endowed with that capability evolve in response to an adaptive process driven by a cellular "survival instinct." Specifically, as tumors proliferate uncontrollably, within them arise pockets characterized by inadequate resource supply, due to failure of the tumor vasculature and the tumor stroma/extracellular matrix (ECM) to keep up with the rapidly increasing tumor cell burden. This generates local areas of low $\mathrm{pH}$, high inflammation, and insufficient stromal supportive network necessary to maintain the survival of the tumor cells. As a result, the majority of the tumor cells within these pockets die but few evolve by activating mechanisms that allow them to survive in the absence of abundant nutrient supply, evade immune recognition, and persist without the strong attachment to the ECM. These newly emergent "super-cells" become "refugees" from the primary tumor, invisible to most diagnostic/imaging modalities and resistant to most currently available therapeutic modalities.

Against this conceptual framework, it appears that most traditional therapeutic approaches against cancer are in some ways counterintuitive. Chemotherapy, radiation therapy, antiangiogenic therapy, etc., indiscriminately induce tumor cell apoptosis. This promotes the creation of inhospitable pockets within the primary tumor and, consequently, stimulates the evolution of aggressive, metastatic "super-clones." To our knowledge, this aspect of tumor progression represents a void in the currently available therapeutic approaches against cancer. Yet, this is the most pernicious, deadly aspect of malignancy. An alternative therapeutic approach suggested by this logic would involve the elimination of factors that would deprive local tumor cells of resources necessary for their survival. An example is presented by the concept of vascular normalization.

Another approach that initially seems counterintuitive would involve modulation of the immune response to minimize the destructive effects of an immune system attempting but incapable of completely eradicating the primary tumor. It is well known that tumors characterized by high levels of inflammation are typically associated with poorer response rates and reduced survival. This approach would likely involve re-balancing the immune response from involving mostly non-specific inflammatory processes to being more strictly antigen-specific. Such interventions may lead to stabilization of the primary tumor as an intact mass that is less likely to spawn aggressive, metastatic cells.

\section{EXAMPLES OF THERAPEUTIC INTERVENTIONS THAT FIT THE PARADIGM OF "CANCER STABILIZATION"}

In this outline, we highlight some studies that illustrate the application of therapeutic methods, which are not strictly cytotoxic but rather target the interaction of the tumor cell with its microenvironment or adaptive mechanisms that are essential for the maintenance of a metastatic phenotype (Table 1). The list of referenced studies is far from exhaustive but attempts to capture

TABLE 1 | Selected therapeutic approaches that illustrate the "cancer stabilization" paradigm.

\begin{tabular}{|c|c|c|}
\hline $\begin{array}{l}\text { Therapeutic } \\
\text { approach }\end{array}$ & Agents & Reference \\
\hline Vascular normalization & $\begin{array}{l}\text { Pro-, anti-angiogenic agents } \\
\text { Bevacizumab }\end{array}$ & $\begin{array}{c}(12,33,87) \\
(11,30,73,88,124)\end{array}$ \\
\hline $\begin{array}{l}\text { Restoration of } \\
\text { normoxia }\end{array}$ & $\begin{array}{l}\text { Hyperbaric oxygen } \\
\text { Liposomes loaded } \\
\text { with hemoglobin } \\
\text { Microbubbles loaded } \\
\text { with oxygen }\end{array}$ & $\begin{array}{c}(1,58,66) \\
(28) \\
(20)\end{array}$ \\
\hline $\begin{array}{l}\text { Inhibition of epithelial- } \\
\text { to-mesenchymal } \\
\text { transition }\end{array}$ & $\begin{array}{l}\text { Salinomycin } \\
\text { CAMP regulators }\end{array}$ & $(98,128)$ \\
\hline $\begin{array}{l}\text { Therapies targeting } \\
\text { bioactive lipid signaling }\end{array}$ & $\begin{array}{l}\text { Autotaxin inhibitors } \\
\text { Fingolimod }\end{array}$ & $\begin{array}{c}(35,50,61,97,120) \\
(14,25,107,108,110) \\
\end{array}$ \\
\hline $\begin{array}{l}\text { Bone-resorption } \\
\text { therapy }\end{array}$ & $\begin{array}{l}\text { Anti-resorptive agents } \\
\text { Denosumab }\end{array}$ & $\begin{array}{c}(2,45,49,51,121,129) \\
(62,71)\end{array}$ \\
\hline Immunotherapy & $\begin{array}{l}\text { Ipilimumab } \\
\text { Pembrolizumab/Nivolumab } \\
\text { Atezolizumab }\end{array}$ & $\begin{array}{c}(31,70,76,93,96,104 \\
125) \\
(79,109,122,127)\end{array}$ \\
\hline $\begin{array}{l}\text { Metastatic-cell } \\
\text { targeted therapy }\end{array}$ & Anti-miRNA-10b antagomirs & $\begin{array}{c}(5,83,84,111) \\
(86,133)\end{array}$ \\
\hline
\end{tabular}


both clinical and preclinical evidence that fits the paradigm of "cancer stabilization" for therapy.

\section{Tumor Vasculature Normalization}

One approach that could limit the emergence of aggressive metastatic subclones would involve modification of the primary tumor microenvironment. Directing the primary tumor toward being a more cohesive, organized, and insulated mass through physicochemical encapsulation and/or normalization of the tumor microenvironment could prevent the escape of tumor cells or minimize the selective pressure that yields subclones capable of dissemination.

Evidence in favor of this concept comes from experience with anti-angiogenic therapy. Anti-angiogenic therapies have been investigated since the early 1970s (3-5). Traditional antiangiogenic therapy focused on the inhibition of the formation of new vessels and the ablation of established vessels in order to limit the supply of oxygen, nutrients, and cytokines to the tumor $(4,6,7)$. With specific relevance to metastasis, though, preclinical studies have shown that metastatic progression could be accelerated by anti-angiogenic therapies (8-11).

An alternative method that is sensible in the context of tumor "stabilization" relies on tumor vasculature normalization. Whereas physiological angiogenesis is important in the natural process of development, reproduction, and repair, pathological angiogenesis, seen in tumors, is characterized by the formation of abnormal vasculature that is leaky, irregular, and heterogeneous. This network of blood vessels is inefficient at effectively delivering oxygen, nutrients, and cytokines to all cancer cells within the tumor. This induces the formation of hypoxic pockets in areas to which oxygen cannot diffuse (100-200 $\mu \mathrm{m}$ away from blood vessels) $(12,13)$. In addition, the irregular vasculature within tumors can lead to the build-up of high interstitial fluid pressure that could drive metastatic cancer cells into blood vessels or the lymphatic fluid network (14).

Contrary to traditional anti-angiogenic approaches, the key concept of vascular normalization is to recover the balance between pro-angiogenic and anti-angiogenic stimuli and consequently induce the repair of the irregular intratumoral blood vessel network, the enhancement of intratumoral oxygenation, and the decrease of interstitial fluid pressure (15-17).

A number of preclinical and clinical trials have shown evidence of the potential success of vascular normalization therapy $(18,19)$. In all cases, the effects of anti-angiogenic therapies via vascular normalization were characterized by the increase of oxygenation, less tortuosity, thinner vessel diameter, and decreased vessel density, which resulted in less permeability, higher blood flow, lower interstitial fluid pressure, and higher perfusion. Following vascular normalization, cancer cells became more responsive to chemotherapy, radiation therapy, and immunotherapy and less prone to metastasis (18).

A key example is presented by the blockade of VEGF-related pathways for effective vascular normalization through the normalization of the endothelial layer (20-23). In clinical trials, chemotherapy combined with bevacizumab (humanized monoclonal antibody against VEGF) improved survival in patients with metastatic cancer of the breast, kidneys, colon, and lung (24-28). This seemingly unexpected effect was explained by a hypothesis first proposed by Rakesh Jain from Harvard Medical School. In their seminal studies, the authors observed time- and dosedependent transient vascular normalization following treatment with the anti-VEGF agent in rectal carcinoma patients. A single infusion of bevacizumab mediated a decrease in vascular volume, tumor perfusion, and microvascular density, resulting in an overall reduction in interstitial fluid pressure (Figure 1). These data led to the conclusion that VEGF inhibition mediates an antivascular effect in clinical cancer (29).

In addition to the patho-physiological changes induced by vascular normalization, there is also enhancement of drug delivery. The Enhanced Permeation-Retention (EPR) effect is very effective for the delivery of large-sized particles or protein conjugates via passive targeting. The leaky vasculature, the main route of drug delivery based on the EPR effect, is repaired during the process of vascular normalization, leading to improvement in the delivery of large particles to tumors, as shown in models of breast cancer (30).

The recent past has revealed another nuance in the utility of vasculature normalization for cancer therapy. Specifically, convincing evidence is emerging of the synergism between immunotherapy and vascular normalization therapy. On the one hand, vascular normalization minimizes hemodynamic obstacles to T lymphocyte infiltration. On the other hand, $\mathrm{CD}^{+}$ $\mathrm{T}$ lymphocyte inactivation leads to increased vessel tortuosity, suggesting reciprocal regulation between $\mathrm{T}_{\mathrm{H}} 1$ cells and vascular status, as shown in models of mammary carcinoma (31).

Despite its promise, vascular normalization has certain limitations. First, it is not a permanent or long-lasting condition, but a transient state. Pharmacologically, it has a "time window" that is established 1-2 days from the time point of anti-angiogenic treatment. After this "time-window," vascular normalization ends irreversibly and does not recover (32). Second, vascular normalization can be established only when pro- and anti-angiogenic factors are well balanced, which requires precise control over the dose of anti-angiogenic therapeutics.

\section{Restoration of Normoxia}

An alternative approach to tumor vascular normalization would involve restoration of normoxia in the tumor microenvironment. When the concentration of oxygen in the tumor is below normal (normoxia), the tumor is defined as "hypoxic" $(33,34,35)$. Hypoxia stimulates cancer cells to secrete signaling molecules for the activation of hypoxia-associated pathways, mainly including HIF, PI3K/AKT/mTOR, MAPK (or ERK), and NFkB (36-40).

The HIF pathway is most important in cancer cell proliferation, survival, apoptosis, metabolism, migration, and inflammation. In normoxia, oxygen sensors (PHD and FIH-1) regulate the expression level of HIF- $\alpha$ subunits (HIF-1 $\alpha$, HIF- $2 \alpha$, and HIF-3 $\alpha$ ) in endothelial cells to convert hydroxylated HIF- $\alpha$ subunits, which are consequently degraded by proteasomes. In contrast, oxygen sensors are deactivated in hypoxia and cannot hydroxylate HIF- $\alpha$ subunits. Unhydroxylated HIF- $\alpha$ subunits are stable. They move to the nucleus, form dimers with HIF- $\beta$, 

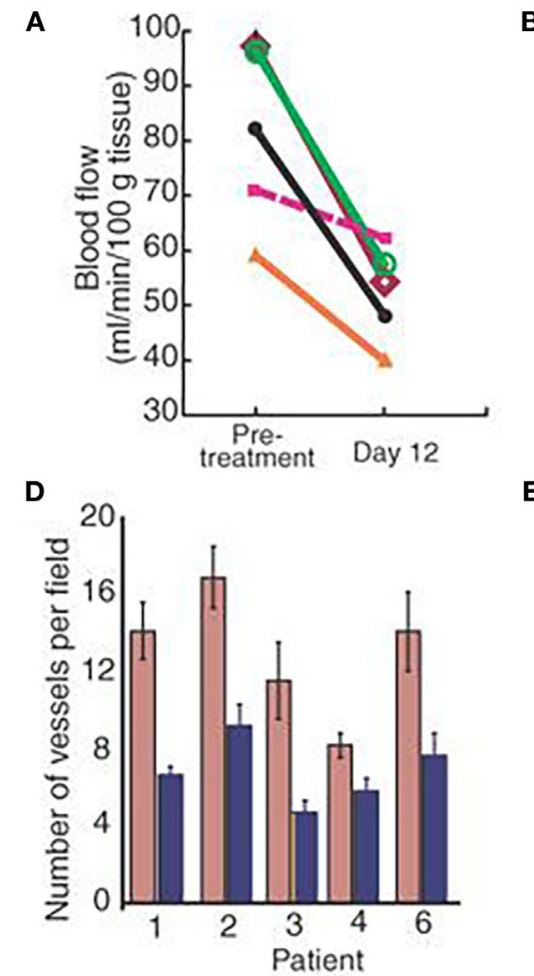

G

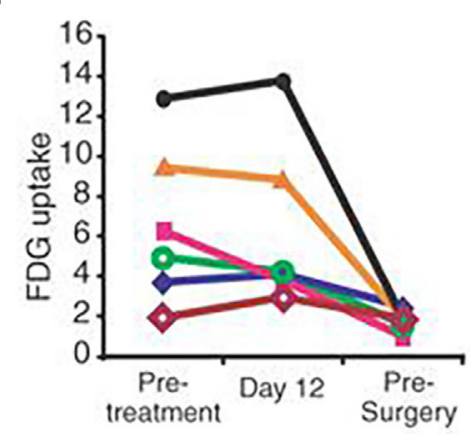

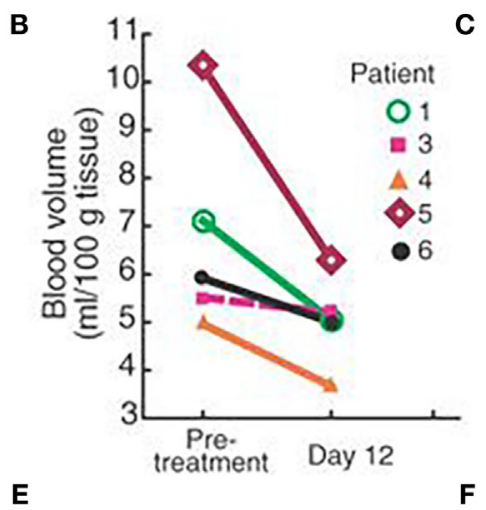
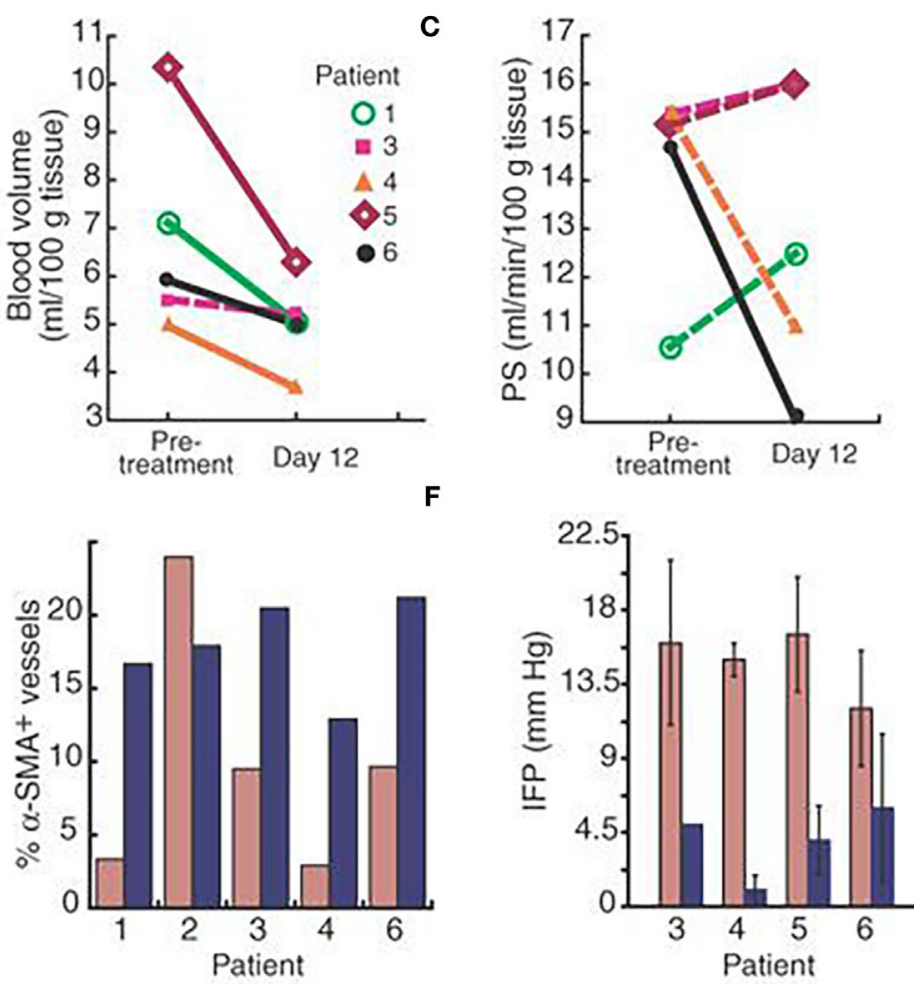

Pretreatment Day 12

H

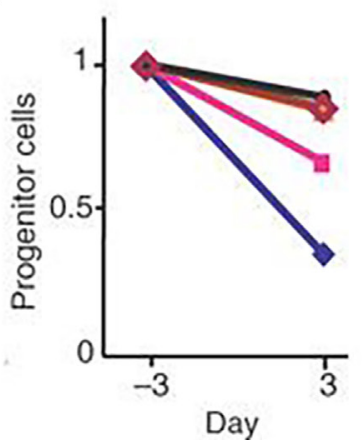

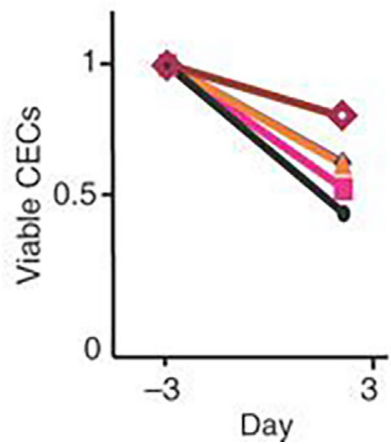

FIGURE 1 | Clinical evidence that vascular normalization through a single infusion of the VEGF-specific antibody bevacizumab is effective in rectal carcinoma patients. "Parameters were obtained pretreatment and after one bevacizumab infusion. (A-C) Blood perfusion (A), blood volume (B), and permeability-surface area product [PS (C)]. Significant decreases after treatment are indicated by solid lines $(P<0.05$ by $t$-test). Blood flow and blood volume decreased significantly in four of the patients. (D) Microvascular density. All patients showed significant decreases after treatment $(P<0.05$ by $t$-test). (E) Fraction of vessels with pericyte coverage. The difference in the fraction of vessels positive for alpha-smooth muscle actin (alpha-SMA) in patient 2 was identified as an outlier by the Extreme Studentized Deviate test. Paired $t$-test analyses of the mean values that included and excluded the data of patient 2 had $P<0.09$ and 0.001 , respectively. (F) Mean tumor IFP decreased significantly after bevacizumab $(P<0.01$ by paired $t$-test). (G) Tumor FDG uptake before treatment, on day 12 and presurgery (day 93), normalized for muscle values. On day 12 after bevacizumab treatment, a $40 \%$ decrease was observed in patient 3 , and no change in the other patients. Lower levels were found in all patients before surgery except for patient 5, who had low levels throughout the treatment. In comparison to pretreatment and day 12 values, the median standard uptake value was significantly lower on day $93(P<0.01)$. (H) Circulating progenitor/stem cells (AC133+; left) and viable CECs (right) in peripheral blood. Samples were run to acquire 50,000 events in the mononuclear/lymphocyte gate. For both cell populations, bevacizumab induced a significant decrease in mean values ( $P<0.05$ by Wilcoxon signed-rank test). Key in (B) applies to (A,C,G-I)." Reprinted from Willett et al. (29) with kind permission by Nature Publishing Group.

and initiate transcription of compensatory targets (41-44). The HIF pathway regulates hundreds of genes and facilitates tumor growth by the promotion of metabolism and angiogenesis
$(45,46,47,48,49)$. In addition, HIF- $\alpha$ promotes metastasis by regulating epithelial-to-mesenchymal transition (EMT) through ZEB-1, ZEB-2, E-cadherin, and TCF3, and migration/ 
invasion through MMP-2 and MMP-9, CXCR4, CAIX, and LOX (50-54). Also, HIF- $\alpha$ interacts with other oncologic pathways. For example, the combination of the HIF- $1 \alpha$ and NFkB pathways is associated with the regulation of more than 1,000 oncologic or inflammatory genes. Furthermore, cancer cells that experience EMT transition in hypoxia are more resistant to chemotherapy as well as to radiation therapy. In normoxia, oxygen mediates sensitivity to radiotherapy by reacting with free radicals produced by ionized radiation. This mechanism triggers DNA damage. In contrast, cancer cells in hypoxic conditions are less sensitive to radiation due to limited generation of DNA radicals (55).

One approach that attempts to restore normoxia is hyperbaric oxygen (HBO) therapy. The goal of HBO therapy is to improve or cure disorders by increasing oxygen levels in plasma and tissue (56). HBO therapy showed a significant increase in $\mathrm{pO}_{2}$ in tumor tissue, which was preserved clinically for $30 \mathrm{~min}$ (57-60). Consequently, HBO therapy induced the activation of the pro-apoptotic MAPK pathway and the downregulation of members of the anti-apoptotic ERK pathway in hematopoietic cells. The same results were obtained in preclinical studies demonstrating the induction of cell death and the inhibition of cell proliferation (61-63). With regard to metastasis, $\mathrm{HBO}$ therapy has resulted in the induction of mesenchymalto-epithelial transition (MET), associated with a less invasive tumor cell phenotype. This result implies that HBO therapy could be useful for the potential inhibition of the metastatic process $(64,65)$.

A more targeted therapeutic approach involves oxygen delivery to tumors using delivery vehicles, including microbubbles and hemoglobin encapsulated liposomes (66-68). The use of delivery vehicles could reduce the risk of oxygen toxicity or eliminate undesirable off-target effects that could be associated with $\mathrm{HBO}$ therapy $(69,70)$.

Microbubbles are typically utilized as contrast agents for ultrasound imaging and sonodynamic therapy. They comprise a lipid, protein, natural, or synthetic polymer as an outer shell and a gaseous core (71-76). The microbubble allows free gas diffusion across its shell, allowing one to regulate the amount of oxygen delivered to tissue depending on how much dissolved gas is found in the local microenvironment. Microbubbles, therefore, acquire oxygen in the lungs and release it in hypoxic tissues. In preclinical studies, oxygen microbubbles reduced the expression of HIF- $1 \alpha$ by $50 \%$ in cancer cells cultured in hypoxic conditions. This resulted in significant reduction in tumor volume after sonodynamic therapy $(73,77)$.

We would like to specifically highlight a more recent preclinical study, which described the design and application of oxygen-loaded microbubbles (O2MB) for pancreatic cancer therapy. O2MBs were designed to incorporate either Rose Bengal or 5-fluorouracil. Treatment with either type of micro-bubble in human xenograft models of pancreatic cancer resulted in reduction in tumor growth, illustrating the capability of microbubble-delivered oxygen to the tumor to enhance therapeutic efficacy, albeit in a somewhat artificial setting of a subcutaneously implanted model (Figure 2).
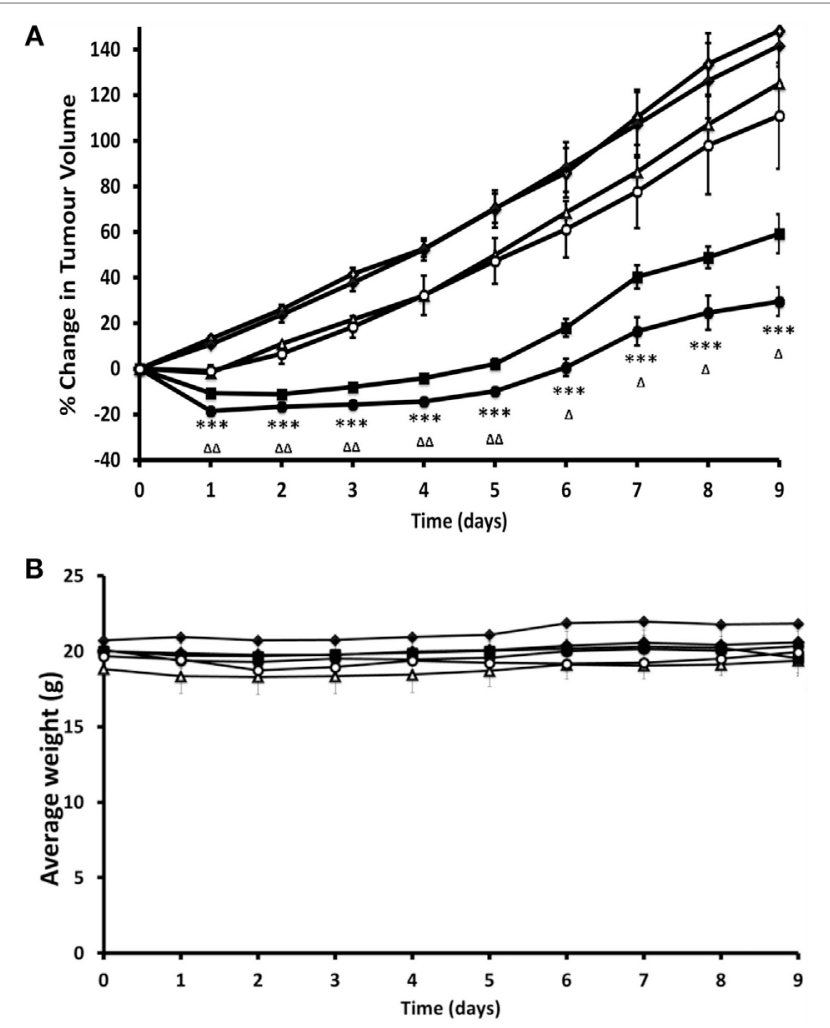

FIGURE 2 | Preclinical evidence that restoration of normoxia through treatment with oxygen-loaded microbubbles $\left(\mathrm{O}_{2} \mathrm{MB}-\mathrm{RB}\right)$ is effective in a murine model of pancreatic cancer. Ectopic human xenograft BxPC-3 tumors were established in the rear dorsum of SCID mice. Plot of (A) \% change in tumor volume and (B) average body weight for mice treated with (i) no treatment (open diamonds), (ii) ultrasound only (filled diamonds), (iii) gemcitabine (open triangles), (iv) $\mathrm{O}_{2} \mathrm{MB}-\mathrm{RB} / \mathrm{O}_{2} \mathrm{MB}-5 \mathrm{FU}$ mix - US (open circles), (v) $\mathrm{O}_{2} \mathrm{MB}-\mathrm{RB}+\mathrm{US}$ (filled squares), (vi) $\mathrm{O}_{2} \mathrm{MB}-\mathrm{RB} / \mathrm{O}_{2} \mathrm{MB}-5 \mathrm{FU}$ mix + US (filled circles). Not shown for ease of illustration are treatments with 5-FU alone, $\mathrm{O}_{2} \mathrm{MB}-\mathrm{RB}-\mathrm{US}, \mathrm{O}_{2} \mathrm{MB}-5 \mathrm{FU}+\mathrm{US}, \mathrm{O}_{2} \mathrm{MB}-5 \mathrm{FU}-\mathrm{US}$. The RB, 5-FU and gemcitabine concentrations were kept constant in each case at $0.184 \mathrm{mg} / \mathrm{kg}(90.8 \mu \mathrm{M}), 0.115 \mathrm{mg} / \mathrm{kg}(440 \mu \mathrm{M})$, and $0.264 \mathrm{mg} / \mathrm{kg}$ $(440 \mu \mathrm{M})$, respectively. Ultrasound treatment was delivered for $30 \mathrm{~s}$ at frequency of $1 \mathrm{MHz}$, an ultrasound power density of $3.0 \mathrm{Wcm}^{-2}$ and a duty cycle of $50 \%$, pulse frequency $=100 \mathrm{~Hz}$. Error bars represent \pm SE where $n=4 .{ }^{*} P<0.05$, ${ }^{\star \star} P<0.01$, and ${ }^{* \star \star} P<0.001$ for (vi) compared to (i) and $\Delta P<0.05,{ }^{\Delta \Delta} P<0.01$, and ${ }^{\Delta \Delta \Delta} P<0.001$ for (vi) compared to (v). "These results reveal a dramatic reduction in tumor volume for mice treated with the combined SDT/antimetabolite therapy compared to either gemcitabine or 5-FU treatment alone." Reprinted from Mcewan et al. (78) with kind permission by Elsevier Publishing Group.

In addition to the methods described above, other approaches for targeting the hypoxic phenotype have been described. These include targeting of HIFs or other pathways important in hypoxia. However, these approaches rely on inducing cell death in a hypoxic environment or involve direct or indirect HIF inhibition. These studies are discussed in detail in Ref. (79).

Combined, these results support the hypothesis that restoring normoxia in tumor tissue can represent a component in a therapeutic approach aimed at normalizing the tumor microenvironment for the suppression of metastasis. 


\section{Inhibiting Epithelial to Mesenchymal Transition}

During EMT, epithelial cells assume a mesenchymal phenotype and are capable of disengaging from the basement membrane, migrating and invading surrounding tissue (80). In addition, cells that undergo EMT often acquire stem cell-like characteristics including tumor cell initiating properties and chemoresistance (81). It is not surprising then that tumors with EMT features have been associated with poor prognosis in several cancers including breast cancer (82), pancreatic adenocarcinoma (83), hepatocellular carcinoma (84), gastric cancer (85), and nonsmall cell lung cancer (86). Over the last decade, evidence has shown that EMT can be initiated by miRNAs as well as several transcription factors, leading to the activation of several downstream pathways (87).

Targeting the EMT pathway has thus emerged as an area of great therapeutic interest. EMT-targeted therapies could be used to inhibit metastasis in high-risk patients or to partially reverse existing metastatic disease (88). Unfortunately, several challenges exist including difficulties in targeting the miRNAs and transcription factors that induce EMT and an apparent redundancy in the pathways activated by EMT. However, a few approaches have emerged in the last few years.

For example, salinomycin was identified in a screen to detect drugs that would inhibit EMT-induced cancer stem cells, and subsequent studies showed that it inhibits breast cancer metastasis as well (89). More recently, Pattabiraman et al. proposed a "differentiation therapy" whereby increases in intracellular levels of the second messenger, cAMP, led to activation of protein kinase A (PKA) causing mesenchymal human mammary epithelial cells to revert to their epithelial state through a MET (90). Induction of MET caused a dramatic loss not only in their ability to metastasize but also in their tumor-initiating properties
(Figure 3). Thus, salinomcyin and "dedifferentiation therapies" could be used to reduce metastasis.

\section{Therapies Targeting Bioactive Lipid Signaling}

Several small bioactive lipids may also be important mediators of metastasis. Lysophosphatidic acid (LPA) is produced by the soluble enzyme autotaxin (ATX) and can signal through a family of high affinity G protein-coupled LPA receptors that includes six members (LPAR1-6). Signaling through these receptors can induce EMT (91), and overexpression of ATX and LPAR1-6 are common in many cancer types and associated with increased metastases in transgenic animals (92). LPA can be dephosphorylated by lipid phosphate phosphatases (LPPs), which leads to its degradation. LPP1 expression is typically decreased in tumors and restoring its expression leads to decreased metastasis in mice (93).

Autotaxin inhibitors have been shown to reduce lung metastases after systemic injection of the mouse B16F10 melanoma cell line (94). Interestingly, reduced lung metastases were also observed in LPAR1 knockout mice (95). ATX/LPA signaling is an important driver of pulmonary (96), renal (97), and liver fibrosis (98). An ATX inhibitor and an LPAR1 antagonist are currently in trials for idiopathic pulmonary fibrosis (NCT02738801 and NCT01766817) and could be potentially repurposed as an antimetastases therapy.

Another bioactive lipid that has been associated with metastasis is sphingosine-1-phosphate (S1P). Sphingosine is released from ceramide through the actions of ceramidase and then is phosphorylated by sphingosine kinase to generate S1P. S1P can be dephosphorylated back to sphingosine by sphingosine phosphatases, degraded by sphingosine phosphate lyase, or exported out of the cell by a transporter, called spinster 2 (SPNS2), where it can signal to cells through 5 sphingosine receptors (S1P1-5).

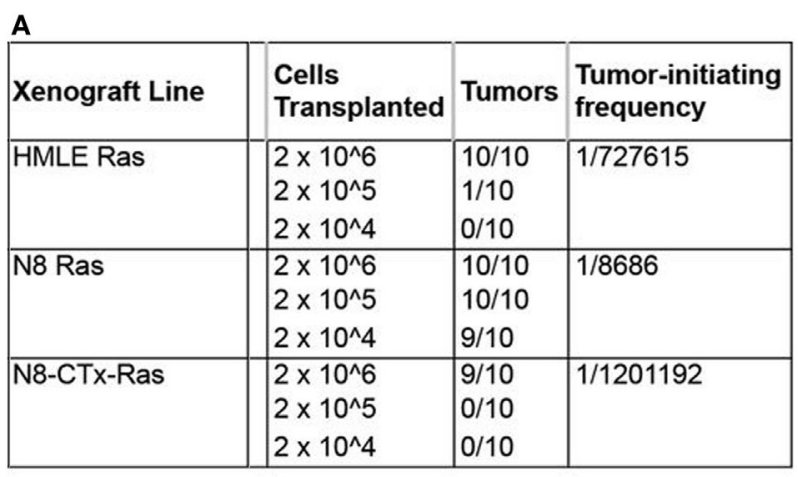

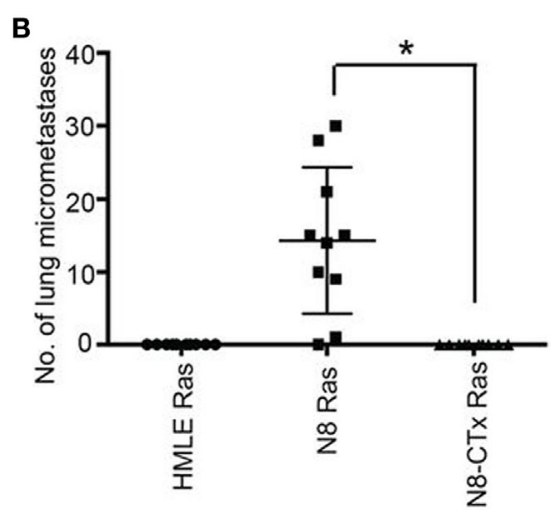

FIGURE 3 | Preclinical evidence that increases in intracellular levels of the second messenger, cAMP, lead to activation of protein kinase A and cause mesenchymal human mammary epithelial cells to revert to their epithelial state, resulting in inhibition of tumor-initiating and metastatic potential. The authors "transplanted at limiting dilutions HMLE-Ras immortalized human mammary epithelial cells and their spontaneously arising mesenchymal derivatives, termed NAMEC8 (N8-Ras) cells, as well as N8-CTx-Ras cells that were mesenchymal-to-epithelial transition (MET) reverted by treatment with cholera toxin (CTx). Cells were implanted into the mammary fat pads of NOD/SCID mice. (A) As anticipated, the frequency of tumor-initiating cells in the N8-Ras cells was far greater than in the HMLE-Ras cell population, in this case, 100-fold higher. Significantly, the N8-CTx-Ras cells were as inefficient at tumor-initiation as the HMLE-Ras cells. (B) The primary tumors that arose upon orthotopic mammary stromal fat pad implantation of N8-Ras tumors spawned 20-30 micrometastases in the lungs by 12 weeks following implantation. This property was completely lost upon induction of an MET by CTx treatment prior to transplantation." Reprinted from Pattabiraman et al. (90) with kind permission by the American Association for the Advancement of Science. 
Lymphocytes sense S1P gradients in the plasma through S1P1 to egress from secondary lymphoid tissues. FTY720 (Fingolimod) was developed as an immunomodulating drug mostly for treating the relapsing form of multiple sclerosis. Fingolimod is phosphorylated forming fingolimod-phosphate. In its phosphorylated form, it can activate lymphocyte S1P1 and ultimately induce S1P1 downregulation, sequestering lymphocytes in lymph nodes and preventing autoimmunity. Interestingly, in animal models, FTY720 has been shown to reduce metastases of several cancers including breast cancer $(99,100)$, liver cancer $(101,102)$, and cholangiocarcinoma (103).

More recently, van der Weyden et al. performed a genomewide in vivo screen of 810 mutant mouse lines, which resulted in the identification of host genes that regulate metastatic colonization in the lung after injection of B16 melanoma cells (104). Their screen identified 23 hits including the S1P transporter Spns2. Further studies demonstrated that deletion of Spns2 created a circulating lymphopenia with increased numbers of natural killer (NK) cells and effector T cells in the lung, which effectively prevent lung colonization (Figure 4). Thus, lipid signaling seems to be an important player in cancer metastasis as well, which could be potentially targeted through several approaches.

\section{Bone-Resorption Therapy}

In addition to modifying the primary tumor microenvironment to prevent the emergence and escape of invasive metastatic
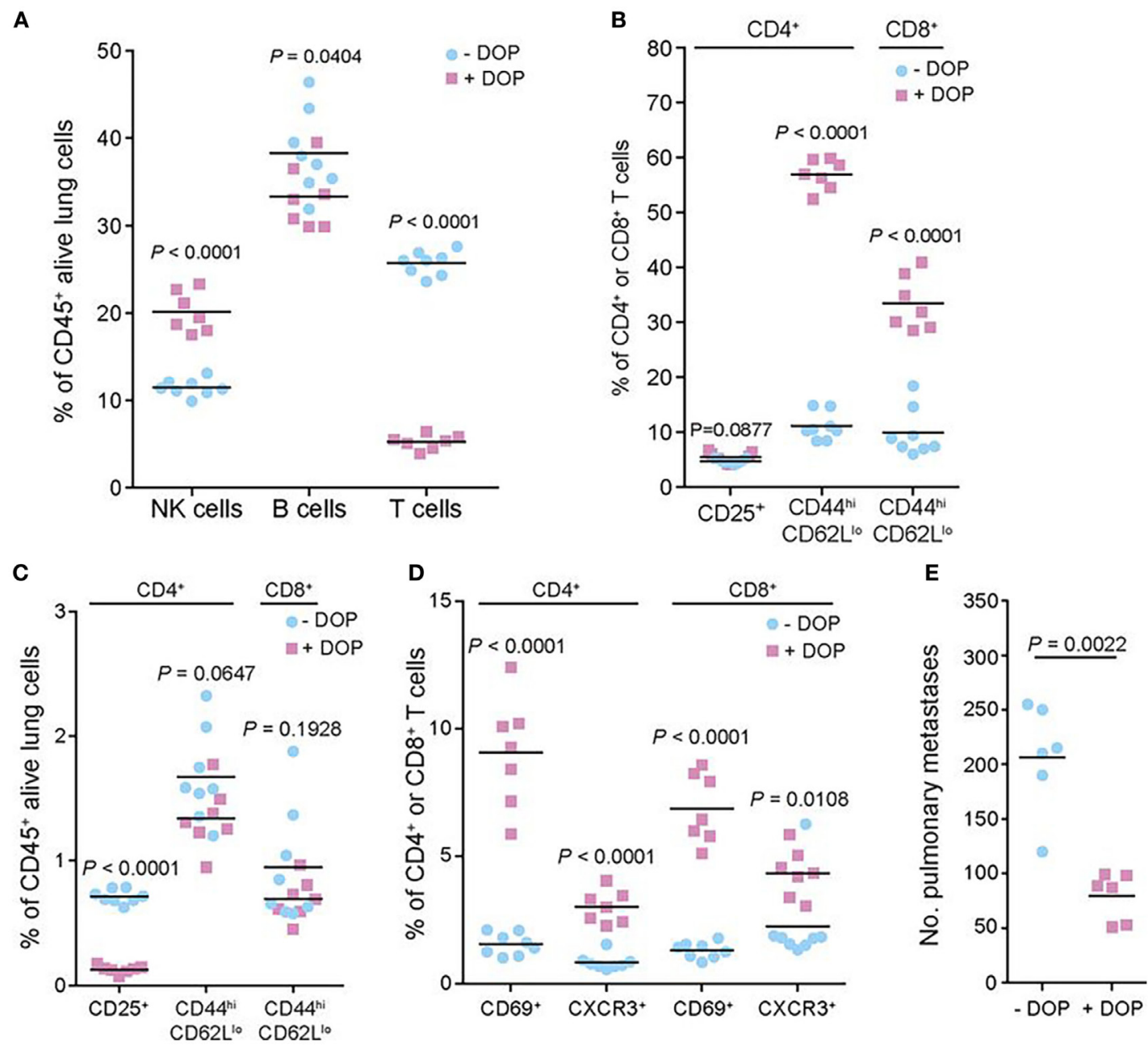

FIGURE 4 | Preclinical evidence in a murine model of melanoma that lipid signaling is an important player in metastasis, which could be potentially targeted for therapy. The authors performed a genome-wide in vivo screen of 810 mutant mouse lines, which resulted in the identification of host genes that regulate metastatic colonization in the lung after injection of B16 melanoma cells. Their screen identified 23 hits including the sphingosine-1-phosphate (S1P) transporter Spns2. In the studies shown here, the authors manipulated the S1P axis pharmacologically by inhibiting S1P lyase, which degrades S1P, using 4'-deoxypyridoxine (DOP), a compound previously shown to increase lymphoid tissue S1P levels and induce a circulating lymphopenia. The studies shown here demonstrated that deletion of Spns2 by DOP treatment created a circulating lymphopenia with increased numbers of natural killer cells and effector T cells in the lung, which effectively prevented lung colonization. (A,C) Number of leukocytes and T cell subsets present in the lungs of B16-F10-dosed glucose- or DOP-treated wild-type male mice presented as the percentages of viable CD45+ lung leukocytes. (B,D) Number of leukocytes and T cell subsets presented as the percentages of viable parent CD4+ or CD8 ${ }^{+}$ T cells. (E) Experimental metastasis assay in B16-F10 dosed glucose- or DOP-treated wild-type female mice. Reprinted from van der Weyden et al. (104) with kind permission by the Nature Publishing Group. 
cells, it is possible to modify the local tissue microenvironment of a distant vital organ, such as the lungs, liver, brain, or bone. Modification of the distant organ microenvironment would make that organ inhospitable to the metastatic tumor cell and limit the establishment and growth of metastatic lesions.

One organ that is commonly colonized in the process of metastasis is bone. Bone provides a unique environment that is characterized by dynamic interplay between multiple cell types including mesenchymal cells (osteocytes, osteoblasts, and adipocytes), hematopoietic cells (immune cells and osteoclasts), endothelial cells, and pericytes (105). In the process of metastasis, circulating tumor cells attach to bone and initiate a cascade of signaling events that promote tumor cell survival in this new microenvironment.

Tumor cells can stimulate the osteoclast lineage to accelerate differentiation, which results in more rapid osteoclastic bone resorption than osteoblastic bone formation. This excessive bone degradation forms cavities in bone where tumor cells can settle to form osteolytic metastatic lesions. Conversely, tumor cells can also excrete cytokines to stimulate osteoblast differentiation and deposition of new bone tissue, causing faster bone formation than resorption, and resulting in excessive bone growth at the sites occupied by metastatic lesions (106).

Therapeutic approaches include anti-resorptive drugs, which have shown excellent therapeutic efficacy in malignancies, such as prostate, breast, lung, and multiple myeloma (107-112). A specific example is presented by bisphosphonates, which are ingested by osteoclasts and result in osteoclast cytotoxicity, effectively limiting osteoclastic bone resorption, as shown in mammary cancer models (113). Interestingly, antibodies developed for the treatment of osteoporosis inhibited bone metastasis by remodeling bone structure in breast cancer patients (114).
A related therapeutic agent targets a molecule, called RANKL, which is secreted by osteoblasts. RANKL attaches to RANK (located on osteoclasts) and stimulates osteoclastic activity. This therapeutic agent (Denosumab) is a human monoclonal antibody against RANKL, which prevents the interaction between RANKL and RANK, and inhibits osteoclastic activity. Denosumab is FDA approved and has shown promising results in patients, including a prolonged time to skeletal-related event (115). In a phase 3 study, denosumab was compared to the bisphosphonate zoledronic acid for the treatment of castration-resistant prostate cancer. The median time to "first on-study skeletal-related event" was 20.7 months with denosumab vs. 17.1 months with zoledronic acid (Figure 5), leading the authors to conclude that denosumab represents a viable treatment option against bone metastases from castration-resistant prostate cancer.

Additional therapeutic approaches for bone metastatic disease include radioisotopes, which incorporate into bone and deliver ionizing radiation, chemotherapy, hormonal therapy, and more modern targeted immunotherapy. However, these approaches primarily target the metastatic tumor cell and are beyond the scope of the current review. For a thorough review on this topic, we direct the reader to Gdowski et al. (116).

\section{Immunotherapy}

The last decade has witnessed impressive progress in the field of immunotherapy. Recent evidence of robust clinical responses has been seen in multiple malignancies, including metastatic melanoma, non-small cell lung cancer, head and neck cancer, renal cell carcinoma (RCCs), breast cancer, and hematological malignancies (117).

Partly, the reason behind this success is the capacity of these interventions to suppress tolerance to tumor antigens. The

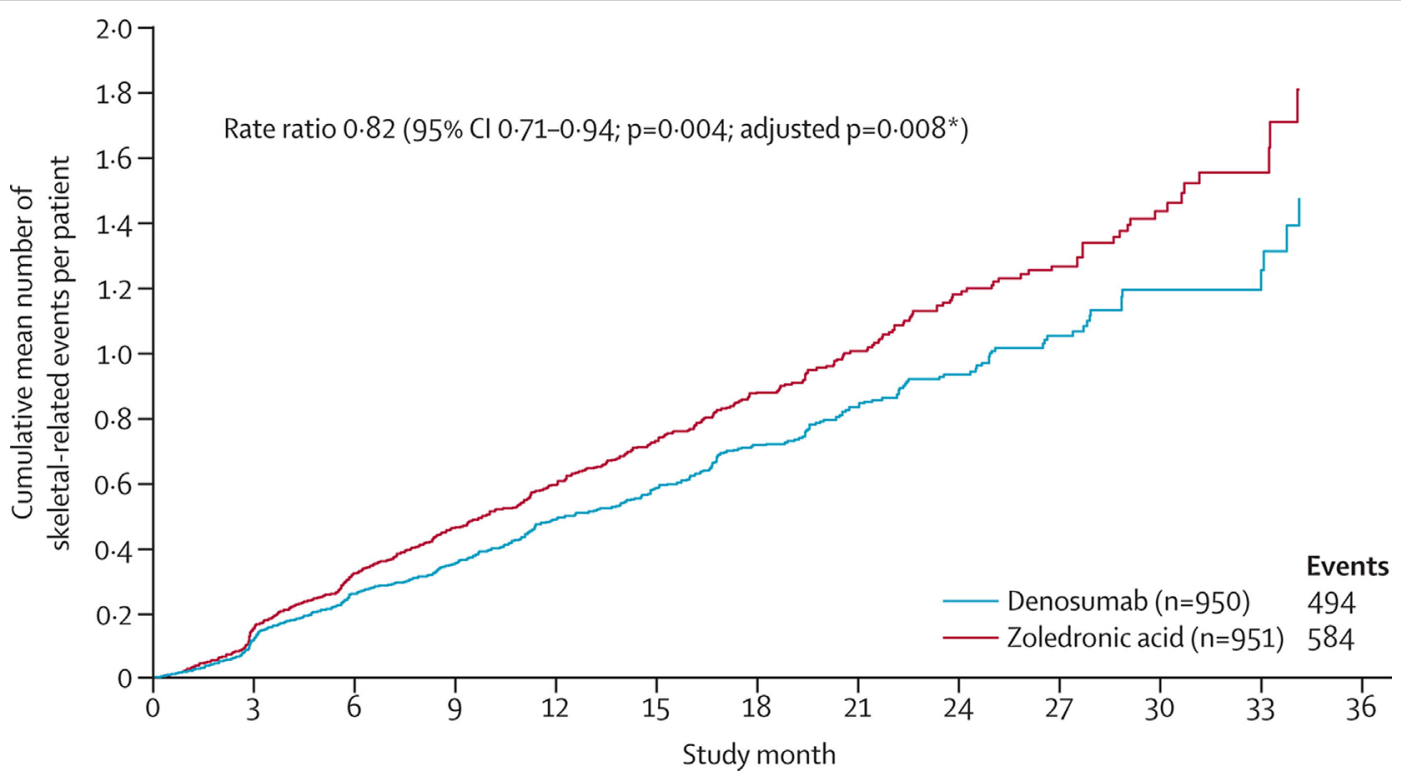

FIGURE 5 | Clinical evidence that anti-osteoclastic therapy can be effective in patients with castration-resistant prostate cancer. "Time to first and subsequent on-study skeletal-related events in prostate cancer patients treated with denosumab vs. zoledronic acid." Reprinted from Fizazi et al. (115) with kind permission by Elsevier. 
immunotherapeutic approaches available now include cancer vaccines, checkpoint inhibitors, oncolytic viruses, and adoptive T-cell or NK cell transfer. Here, we will focus on immune checkpoint inhibitors because they fit more closely the paradigm of restoring immunological homeostasis in the tumor microenvironment.

It is well-known that tumor cells have developed efficient mechanisms to escape immune recognition. These include tolerance induction, immune evasion, and interference with $\mathrm{T}$ cell signaling. To avoid immune recognition, tumor cells highjack the body's system of checks and balances that controls $\mathrm{T}$ cell mediated cellular immunity.

Specifically, when the $\mathrm{T}$ cell receptor (TCR) of a $\mathrm{T}$ cell recognizes foreign antigens in the context of the major histocompatibility complex, additional binding events modulate the ensuing response through co-stimulatory factors, such as CD28 (serving to amplify the signal by binding to CD80/CD86 on antigen-presenting cells) or immune checkpoint molecules, such as CTLA-4 or PD-1 (to suppress the signal by binding to CD80/ CD86 on antigen-presenting cells or PD-L1 on tumor cells or activated macrophages). Upregulation of PD-L1 on tumor cells leads to engagement of PD-1 on T lymphocytes and suppression of the cytotoxic immune response even in the presence of proper recognition of tumor antigen by the TCR. Conversely, pharmacological PD-1/PD-L1 inhibition prevents the PD-1/ PD-L1 interaction, facilitating the mounting of an effective cytotoxic response.

A thorough review on this subject can be found in Alsaab et al. (117) and Farkona et al. (118). Here, we would like to highlight the clinical progress that has been made using CTLA-4 and PD-1 inhibitors. Ipilimumab, an anti-CTLA-4 antibody, was approved by the FDA in 2011, following successful phase III clinical trials in patients with metastatic melanoma (119-121). More recently, testing in clinical trials was initiated for the treatment of non-small cell lung carcinoma (NSCLC), small cell lung cancer, bladder cancer, and metastatic hormone-refractory prostate cancer. Despite this early success, it has become clear that CTLA-4 blockade is likely to help only a small fraction of patients and could result in grades 3-5 (severe) immune-related adverse events in $10-35 \%$ of patients (122). In addition, response to ipilimumab may take several months to manifest, making it difficult to assess therapeutic efficacy $(118,123)$.

Promising clinical results have been obtained using antibodies against the PD1-PD-L1 axis. These include pembrolizumab (previously named as lambrolizumab; anti-PD1) and nivolumab (anti-PD1) (124). A lot of the excitement over therapy with checkpoint inhibitors rests on the robust therapeutic responses seen in some patients with these agents. In clinical trials for melanoma, nivolumab was associated with often durable clinical responses (125). A case report is presented in Figure 6. The study illustrates successful therapy with nivolumab in a patient with metastatic mucosal melanoma who ultimately achieved a durable complete response (126).

The anti-PD-L1 antibody atezolizumab has shown promise in a wide range of malignancies, including colon, lung, renal cell, gastric, head and neck cancer, and melanoma. Clinical approval has been obtained for pembrolizumab and nivolumab

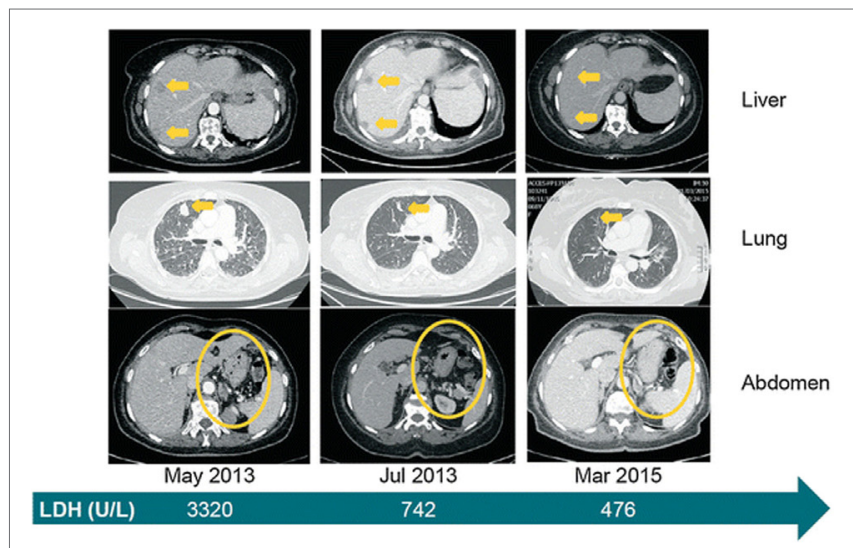

FIGURE 6 | Clinical evidence that treatment with the immune checkpoint inhibitor, nivolumab is effective against metastatic mucosal melanoma. Systemic clinical response to nivolumab treatment. Computed tomography images from baseline (May 2013), 2 months into treatment and approximately 2 years later. Yellow arrows or circles indicate metastatic foci and their complete disappearance by March 2015. The green arrow depicts the level of $\mathrm{LDH}$ at the selected time points. $L D H$ lactate dehydrogenase. Reprinted from Ascierto et al. (126) with kind permission by Springer Berlin Heidelberg.

for melanoma and NSCLC, whereas nivolumab has also been approved for RCC (121) and metastatic urothelial carcinoma [reviewed in Farkona et al. (118)].

In addition to the robust durable therapeutic responses that have been achieved with PD-1-PD-L1 inhibitors, these agents have also displayed a manageable toxicity profile. Unlike CTLA-4 inhibitors, PD-1 inhibitors are associated with mild immunostimulation that can be treated with supportive care and steroid administration (118).

Taken together, these observations suggest that metastatic cancer could be managed successfully by restoring homeostasis in the immunological microenvironment of the tumor cell. The unprecedented success of cancer immunotherapy hints at the potential of therapeutic approaches that aim to "correct" or "normalize" microenvironmental aspects of cancer emergence and progression, as opposed to interventions that are purely cytotoxic to the tumor cell.

\section{Metastatic-Cell Targeted Therapy}

A successful approach for treating metastasis would invariably include intervention at the level of the metastatic cell. One unique property of metastatic tumor cells that could be targeted for therapy is their resistance to anoikis. Anoikis is a type of programmed cell death, which occurs when anchoragedependent cells detach from the ECM. Healthy cells usually stay associated with the tissue to which they belong since their survival depends critically on communication between proximal cells and the ECM. When these cells are detached from the ECM, they invariably undergo anoikis. By contrast, metastatic tumor cells can become resistant to anoikis. This capability is key to their escape from the primary tumor, survival in the lymphatics or circulation, and ultimately, colonization of other vital organs $(12,127-129)$. Based on this knowledge, it becomes clear that 
by restoring sensitivity to anoikis in metastatic tumor cells, one could trigger programmed cell death in these cells in a way that is efficient and spares healthy cells.

In our search for a therapeutic target that fits this profile, we focused on microRNA-10b as a key initiator of metastasis and driver of resistance to anoikis. In a seminal study, Ma et al. showed that microRNA-10b (miR-10b) was overexpressed in metastatic breast cancer cells and could initiate invasion and metastasis in otherwise non-metastatic cells (130). In patients, miR-10b has been implicated in metastasis and disease outcome of multiple malignancies including lung, breast, gastric, colorectal, bladder, ovarian, pancreatic, hepatocellular, and brain cancer, to name a few (130-132).

In our own studies, we identified miRNA-10b as a master regulator of the viability of metastatic tumor cells. We determined that miR-10b not only promotes the capacity of tumor cells to migrate and invade surrounding tissue (become metastatic) but also serves as a powerful master regulator of the viability of these cells (133-135). Detailed mechanistic studies confirmed the existence of a miR-10b-triggered pathway that regulates the viability and proliferation of tumor cells only after they have acquired the ability metastasize, pointing to miR-10b as a driver of resistance to anoikis (134).

This knowledge allowed us to develop a therapeutic strategy based on miR-10b inhibition. The specific inhibition of miR-10b was achieved using inhibitory oligonucleotides (LNA-based antagomirs) delivered to metastatic sites by dextran-coated iron oxide nanoparticles (termed MN-anti-miR10b). We demonstrated that $\mathrm{MN}$-anti-miR10b could completely prevent the formation of de novo metastases (133) and, when combined with low-dose chemotherapy, caused complete and persistent regression of local lymph node metastasis in a murine breast cancer model (Figure 7) (134).

In a model of Stage IV metastatic breast cancer, we found that a weekly treatment protocol with $\mathrm{MN}$-anti-miR-10b and low-dose doxorubicin demonstrated complete regression of pre-existing lung metastases in $65 \%$ of the animals and inhibition of multiple organ metastases in $94 \%$ of the animals. This translated into a significant reduction in cancer mortality in animals treated with MN-anti-miR10b and low-dose doxorubicin relative to control groups, including a group treated with monotherapy of standard dose doxorubicin, used to model standard-of-care (135).

These studies illustrate the potential of therapeutic approaches that target the unique capability of metastatic tumor cells to survive in the absence of "healthy" cell-cell and cell-stroma interactions and outside of their natural microenvironment. Combined with efficient delivery vehicles, similar targeted therapeutic approaches could provide a means to target cancer on a systemic level.

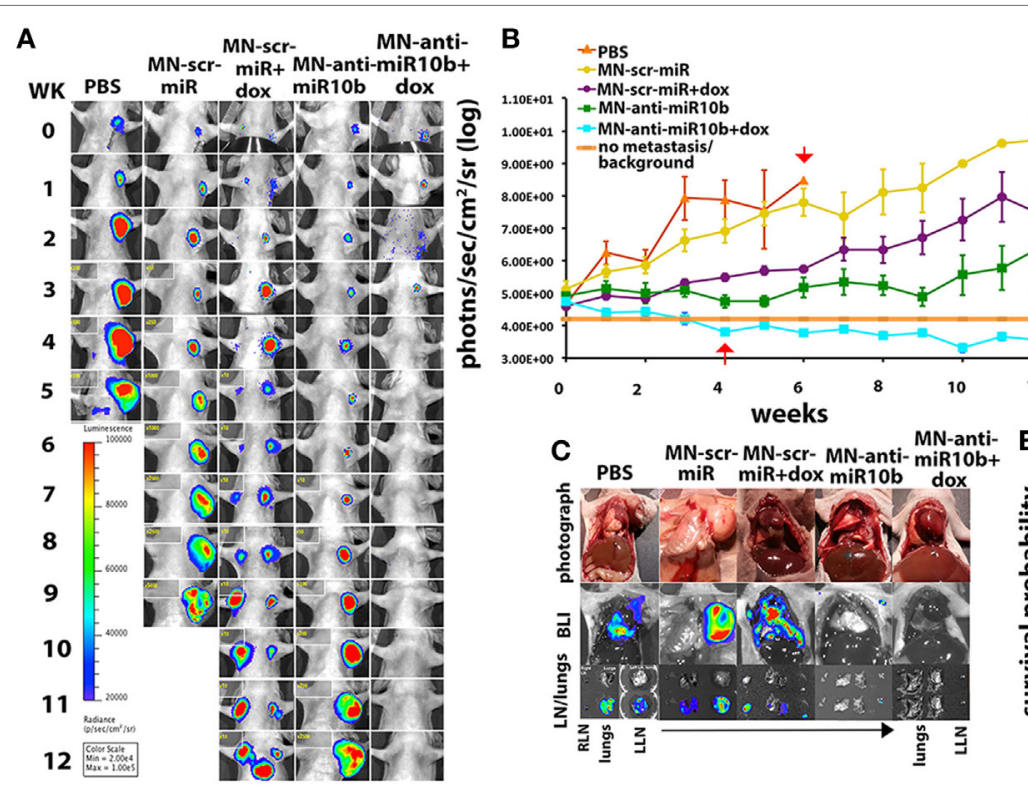

D
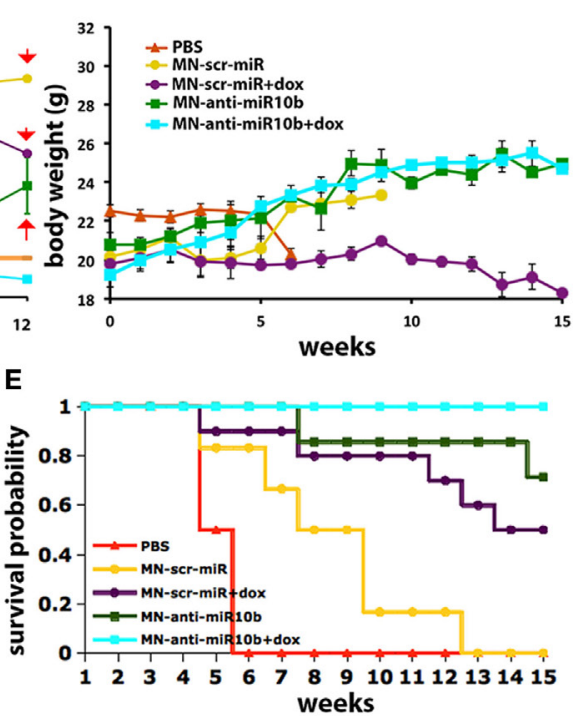

FIGURE 7 | Preclinical evidence that metastatic-cell targeted therapy is effective in a murine model of metastatic breast cancer. "Metastatic burden and survival of mice orthotopically implanted with human breast cancer cells and treated with the miR-10b inhibitor MN-anti-miR-10b and low-dose doxorubicin (Dox). (A) Representative bioluminescence images of metastatic burden showing complete regression of metastases in animals treated with MN-anti-miR-10b and doxorubicin. (B) Quantitative analysis of metastatic burden from all treatment groups, indicating complete regression of metastatic burden in the lymph nodes of experimental animals treated with MN-anti-miR-10b and doxorubicin after just four weekly treatments. Background counts are derived from non-tumor-bearing animals. (C) Ex vivo BLI showing the absence of detectable lymph node or lung metastases in mice treated with MN-anti-miR-10b and doxorubicin. In animals treated with $\mathrm{MN}$-anti-miR-10b alone, there were lymph nodes but not lung metastases. In all other groups, there were both lymph node and lung metastases. (D) Animal weight. The groups treated with MN-anti-miR-10b with or without doxorubicin continued to gain weight throughout the time course of the study. (E) Mortality. Only in the group of animals treated with MN-anti-miR-10b and doxorubicin, there was no mortality from carcinoma. Data, average \pm SEM; withinsubjects ANOVA: $P<0$ 0.05. PBS, $n=2$; MN-scr-miR, $n=6$; MN-scr-miR + Dox, $n=10$; MN-anti-miR-10b, $n=7 ;$ MN-anti-miR-10b + Dox, $n=10$." Reprinted from Yoo et al. (134) with kind permission by AACR. 


\section{CONCLUSION}

The recent past has seen impressive progress in the field of cancer therapy. Still, the outcomes for people diagnosed with advanced metastatic cancer are poor. There has been minimal progress in the overall survival of stage IV malignancy and 5 -year survival rates are still below $20 \%$ for cancers such as pancreatic, bile duct, colorectal, NSCL, liver, gastric, ovarian, and esophageal cancer. These poor outcomes highlight the need to develop strategies different from the traditional cytotoxic approach to cancer therapy that has dominated the field over the past century.

This review outlines a new methodology that consists of three major components. The first component involves modification of the primary tumor microenvironment in order to limit the emergence and escape of invasive tumor cells. The second component entails modification of the microenvironment of the distant metastatic organ in order to make it less hospitable to metastatic tumor cells. The third component includes disruption of anchorage independence and immune tolerance to the tumor cells with the goal of eliciting systemic

\section{REFERENCES}

1. Kroigard AB, Larsen MJ, Thomassen M, Kruse TA. Molecular concordance between primary breast cancer and matched metastases. Breast J (2016) 22(4):420-30. doi:10.1111/tbj.12596

2. Steeg PS. Targeting metastasis. Nat Rev Cancer (2016) 16:201-18. doi:10.1038/ nrc. 2016.25

3. Folkman J. Tumor angiogenesis: therapeutic implications. New Engl J Med (1971) 285:1182-6. doi:10.1056/NEJM197111182852108

4. Folkman J. Anti-angiogenesis: new concept for therapy of solid tumors. Ann Surg (1972) 175:409. doi:10.1097/00000658-197203000-00014

5. Ye W. The complexity of translating anti-angiogenesis therapy from basic science to the clinic. Dev Cell (2016) 37:114-25. doi:10.1016/j.devcel.2016.03.015

6. Bergers G, Benjamin LE. Tumorigenesis and the angiogenic switch. Nat Rev Cancer (2003) 3:401. doi:10.1038/nrc1093

7. Ferrara N, Kerbel RS. Angiogenesis as a therapeutic target. Nature (2005) 438:967. doi:10.1038/nature04483

8. Bergers G, Hanahan D. Modes of resistance to anti-angiogenic therapy. Nat Rev Cancer (2008) 8:592. doi:10.1038/nrc2442

9. Ebos JM, Lee CR, Cruz-Munoz W, Bjarnason GA, Christensen JG, Kerbel RS. Accelerated metastasis after short-term treatment with a potent inhibitor of tumor angiogenesis. Cancer Cell (2009) 15:232-9. doi:10.1016/j.ccr.2009. 01.021

10. Pàez-Ribes M, Allen E, Hudock J, Takeda T, Okuyama H, Viñals F, et al. Antiangiogenic therapy elicits malignant progression of tumors to increased local invasion and distant metastasis. Cancer Cell (2009) 15:220-31. doi:10.1016/j.ccr.2009.01.027

11. Daenen LG, Roodhart JM, Van Amersfoort M, Dehnad M, Roessingh W, Ulfman LH, et al. Chemotherapy enhances metastasis formation via VEGFR-1expressing endothelial cells. Cancer Res (2011) 71:6976-85. doi:10.1158/ 0008-5472.CAN-11-0627

12. Bristow RG, Hill RP. Hypoxia and metabolism: hypoxia, DNA repair and genetic instability. Nat Rev Cancer (2008) 8:180-92. doi:10.1038/nrc2344

13. Dewhirst MW, Cao Y, Moeller B. Cycling hypoxia and free radicals regulate angiogenesis and radiotherapy response. Nat Rev Cancer (2008) 8:425. doi: $10.1038 / \operatorname{nrc} 2397$

14. Rofstad EK, Galappathi K, Mathiesen BS. Tumor interstitial fluid pressurea link between tumor hypoxia, microvascular density, and lymph node metastasis. Neoplasia (2014) 16:586-94. doi:10.1016/j.neo.2014.07.003

15. Jain RK. Normalization of tumor vasculature: an emerging concept in antiangiogenic therapy. Science (2005) 307:58-62. doi:10.1126/science.1104819 regression of metastatic burden. These interventions, along with surgical resection, could conceivably lead to robust therapeutic outcomes in patients with otherwise poor prognosis. As outlined here, first steps in this direction have already been made. Still, the general concept of "stabilization" rather than "eradication" of cancer, as a companion to surgical resection, can spur additional research that could have a transformative impact on the management of metastatic disease.

\section{AUTHOR CONTRIBUTIONS}

$\mathrm{BY}, \mathrm{BF}$, and $\mathrm{ZM}$ performed the conceptualization, the literature search, the data extraction, and composed the manuscript. All the authors contributed substantially to the final manuscript and approved the final version.

\section{FUNDING}

$\mathrm{ZM}$ and BY were supported by R01CA16346101A1 and R01CA135650 from the National Cancer Institute to ZM. BF is supported by NIH grant DK104956.

16. Carmeliet P, Jain RK. Principles and mechanisms of vessel normalization for cancer and other angiogenic diseases. Nat Rev Drug Discov (2011) 10:417. doi:10.1038/nrd3455

17. Huang Y, Goel S, Duda DG, Fukumura D, Jain RK. Vascular normalization as an emerging strategy to enhance cancer immunotherapy. Cancer Res (2013) 73:2943-8. doi:10.1158/0008-5472.CAN-12-4354

18. Goel S, Duda DG, Xu L, Munn LL, Boucher Y, Fukumura D, et al. Normalization of the vasculature for treatment of cancer and other diseases. Physiol Rev (2011) 91:1071-121. doi:10.1152/physrev.00038.2010

19. Goel S, Fukumura D, Jain RK. Normalization of the tumor vasculature through oncogenic inhibition: an emerging paradigm in tumor biology. Proc Natl Acad Sci U S A (2012) 109:E1214-1214. doi:10.1073/pnas.1203794109

20. Mazure NM. Hypoxia signalling in cancer and approaches to enforce tumour regression. Nature (2006) 441:437. doi:10.1038/nature04871

21. Kaelin WG, Ratcliffe PJ. Oxygen sensing by metazoans: the central role of the HIF hydroxylase pathway. Mol Cell (2008) 30:393-402. doi:10.1016/j. molcel.2008.04.009

22. Mazzone M, Dettori D, De Oliveira RL, Loges S, Schmidt T, Jonckx B, et al. Heterozygous deficiency of PHD2 restores tumor oxygenation and inhibits metastasis via endothelial normalization. Cell (2009) 136:839-51 doi:10.1016/j.cell.2009.01.020

23. Madsen CD, Pedersen JT, Venning FA, Singh LB, Moeendarbary E, Charras G, et al. Hypoxia and loss of PHD2 inactivate stromal fibroblasts to decrease tumour stiffness and metastasis. EMBO Rep (2015) 16:1394-408. doi:10.15252/ embr.201540107

24. Hurwitz H, Fehrenbacher L, Novotny W, Cartwright T, Hainsworth J, Heim W, et al. Bevacizumab plus irinotecan, fluorouracil, and leucovorin for metastatic colorectal cancer. N Engl J Med (2004) 350:2335-42. doi:10.1056/ NEJMoa032691

25. Sandler A, Gray R, Perry MC, Brahmer J, Schiller JH, Dowlati A, et al. Paclitaxel-carboplatin alone or with bevacizumab for non-small-cell lung cancer. N Engl J Med (2006) 355:2542-50. doi:10.1056/NEJMoa061884

26. Escudier B, Pluzanska A, Koralewski P, Ravaud A, Bracarda S, Szczylik C, et al. Bevacizumab plus interferon alfa-2a for treatment of metastatic renal cell carcinoma: a randomised, double-blind phase III trial. Lancet (2007) 370:2103-11. doi:10.1016/S0140-6736(07)61904-7

27. Miller K, Wang M, Gralow J, Dickler M, Cobleigh M, Perez EA, et al. Paclitaxel plus bevacizumab versus paclitaxel alone for metastatic breast cancer. N Engl J Med (2007) 357:2666-76. doi:10.1056/NEJMoa072113

28. Liu K, Zhang X, Xu W, Chen J, Yu J, Gamble JR, et al. Targeting the vasculature in hepatocellular carcinoma treatment: starving versus normalizing 
blood supply. Clin Transl Gastroenterol (2017) 8:e98. doi:10.1038/ctg. 2017.28

29. Willett CG, Boucher Y, Di Tomaso E, Duda DG, Munn LL, Tong RT, et al. Direct evidence that the VEGF-specific antibody bevacizumab has antivascular effects in human rectal cancer. Nat Med (2004) 10:145-7. doi: $10.1038 / \mathrm{nm} 0604-649 \mathrm{c}$

30. Chauhan VP, Stylianopoulos T, Martin JD, Popović Z, Chen O, Kamoun WS, et al. Normalization of tumour blood vessels improves the delivery of nanomedicines in a size-dependent manner. Nat Nanotechnol (2012) 7:383-8. doi:10.1038/nnano.2012.45

31. Tian L, Goldstein A, Wang H, Ching, Lo H, Sun Kim I, et al. Mutual regulation of tumour vessel normalization and immunostimulatory reprogramming. Nature (2017) 544:250-4. doi:10.1038/nature21724

32. Winkler F, Kozin SV, Tong RT, Chae S-S, Booth MF, Garkavtsev I, et al. Kinetics of vascular normalization by VEGFR2 blockade governs brain tumor response to radiation: role of oxygenation, angiopoietin-1, and matrix metalloproteinases. Cancer Cell (2004) 6:553-63. doi:10.1016/S1535-6108(04) 00305-8

33. Bottaro DP, Liotta LA. Cancer: out of air is not out of action. Nature (2003) 423:593-5. doi:10.1038/423593a

34. Wilson WR, Hay MP. Targeting hypoxia in cancer therapy. Nat Rev Cancer (2011) 11:393. doi:10.1038/nrc3064

35. Rankin EB, Giaccia AJ. Hypoxic control of metastasis. Science (2016) 352:175-80. doi:10.1126/science.aaf4405

36. Semenza GL. Targeting HIF-1 for cancer therapy. Nat Rev Cancer (2003) 3:721. doi:10.1038/nrc1187

37. Lu X, Kang Y. Hypoxia and hypoxia-inducible factors: master regulators of metastasis. Clin Cancer Res (2010) 16:5928-35. doi:10.1158/1078-0432. CCR-10-1360

38. Tafani M, Pucci B, Russo A, Schito L, Pellegrini L, Perrone GA, et al. Modulators of HIF $1 \alpha$ and NFkB in cancer treatment: is it a rational approach for controlling malignant progression? Front Pharmacol (2013) 4:13. doi:10.3389/ fphar.2013.00013

39. Muz B, De La Puente P, Azab F, Azab AK. The role of hypoxia in cancer progression, angiogenesis, metastasis, and resistance to therapy. Hypoxia (2015) 3:83. doi:10.2147/HP.S93413

40. Mayer IA, Arteaga CL. The PI3K/AKT pathway as a target for cancer treatment. Annu Rev Med (2016) 67:11-28. doi:10.1146/annurev-med-062913051343

41. Maxwell PH, Wiesener MS, Gin-Wen C, Clifford SC. The tumour suppressor protein VHL targets hypoxia-inducible factors for oxygen-dependent proteolysis. Nature (1999) 399:271. doi:10.1038/20459

42. Bruick RK, Mcknight SL. A conserved family of prolyl-4-hydroxylases that modify HIF. Science (2001) 294:1337-40. doi:10.1126/science.1066373

43. Schofield CJ, Ratcliffe PJ. Oxygen sensing by HIF hydroxylases. Nat Rev Mol Cell Biol (2004) 5:343. doi:10.1038/nrm1366

44. Prabhakar NR, Semenza GL. Oxygen sensing and homeostasis. Physiology (2015) 30:340-8. doi:10.1152/physiol.00022.2015

45. Siemeister G, Weindel K, Mohrs K, Barleon B, Martiny-Baron G, Marmé D. Reversion of deregulated expression of vascular endothelial growth factor in human renal carcinoma cells by von Hippel-Lindau tumor suppressor protein. Cancer Res (1996) 56:2299-301.

46. An WG, Kanekal M, Simon MC, Matlepe E. Stabilization of wild-type p53 by hypoxia-inducible factor 1alpha. Nature (1998) 392:405. doi:10.1038/32925

47. Bertout JA, Patel SA, Simon MC. The impact of $\mathrm{O} 2$ availability on human cancer. Nat Rev Cancer (2008) 8:967. doi:10.1038/nrc2540

48. Semenza GL. Hypoxia-inducible factors: mediators of cancer progression and targets for cancer therapy. Trends Pharmacol Sci (2012) 33:207-14. doi:10.1016/j.tips.2012.01.005

49. Semenza GL. HIF-1 mediates metabolic responses to intratumoral hypoxia and oncogenic mutations. J Clin Invest (2013) 123:3664. doi:10.1172/JCI67230

50. Rajpurohit R, Risbud MV, Ducheyne P, Vresilovic EJ, Shapiro IM. Phenotypic characteristics of the nucleus pulposus: expression of hypoxia inducing factor-1, glucose transporter-1 and MMP-2. Cell Tissue Res (2002) 308: 401-7. doi:10.1007/s00441-002-0563-6

51. Staller P, Sulitkova J, Lisztwan J, Moch H. Chemokine receptor CXCR4 downregulated by von Hippel-Lindau tumour suppressor pVHL. Nature (2003) 425:307. doi:10.1038/nature01874
52. Grabmaier K, De Weijert MC, Verhaegh GW, Schalken JA, Oosterwijk E. Strict regulation of CAIXG250/MN by HIF-1 [alpha] in clear cell renal cell carcinoma. Oncogene (2004) 23:5624. doi:10.1038/sj.onc.1207764

53. Erler JT, Bennewith KL, Nicolau M, Dornhöfer N, Kong C, Le Q-T, et al. Lysyl oxidase is essential for hypoxia-induced metastasis. Nature (2006) 440: 1222. doi:10.1038/nature04695

54. Struckmann K, Mertz K, Steu S, Storz M, Staller P, Krek W, et al. pVHL co-ordinately regulates CXCR4/CXCL12 and MMP2/MMP9 expression in human clear-cell renal cell carcinoma. J Pathol (2008) 214:464-71. doi:10.1002/ path. 2310

55. Barker HE, Paget JT, Khan AA, Harrington KJ. The tumour microenvironment after radiotherapy: mechanisms of resistance and recurrence. Nat Rev Cancer (2015) 15:409. doi:10.1038/nrc3993

56. Gill A, Bell CN. Hyperbaric oxygen: its uses, mechanisms of action and outcomes. QJM (2004) 97:385-95. doi:10.1093/qjmed/hch074

57. Brizel D, Lin S, Johnson J, Brooks J, Dewhirst M, Piantadosi C. The mechanisms by which hyperbaric oxygen and carbogen improve tumour oxygenation. Br J Cancer (1995) 72:1120. doi:10.1038/bjc.1995.474

58. Kinoshita Y, Kohshi K, Kunugita N, Tosaki T, Yokota A. Preservation of tumour oxygen after hyperbaric oxygenation monitored by magnetic resonance imaging. Br J Cancer (2000) 82:88. doi:10.1054/bjoc.1999.0882

59. Beppu T, Kamada K, Yoshida Y, Arai H, Ogasawara K, Ogawa A. Change of oxygen pressure in glioblastoma tissue under various conditions. J Neurooncol (2002) 58:47-52. doi:10.1023/A:1015832726054

60. Dewhirst MW, Birer SR. Oxygen-enhanced MRI is a major advance in tumor hypoxia imaging. Cancer Res (2016) 76(4):769-72. doi:10.1158/0008-5472. CAN-15-2818

61. Raa A, Stansberg C, Steen VM, Bjerkvig R, Reed RK, Stuhr LE. Hyperoxia retards growth and induces apoptosis and loss of glands and blood vessels in DMBA-induced rat mammary tumors. BMC Cancer (2007) 7:23. doi:10.1186/ 1471-2407-7-23

62. Stuhr LEB, Raa A, Øyan A, Kalland K, Sakariassen P, Petersen K, et al. Hyperoxia retards growth and induces apoptosis, changes in vascular density and gene expression in transplanted gliomas in nude rats. J Neurooncol (2007) 85:191-202. doi:10.1007/s11060-007-9407-2

63. Moen I, Stuhr LE. Hyperbaric oxygen therapy and cancer-a review. Target Oncol (2012) 7:233-42. doi:10.1007/s11523-012-0233-x

64. Moen I, Øyan AM, Kalland K-H, Tronstad KJ, Akslen LA, Chekenya M, et al. Hyperoxic treatment induces mesenchymal-to-epithelial transition in a rat adenocarcinoma model. PLoS One (2009) 4:e6381. doi:10.1371/journal. pone. 0006381

65. Finger EC, Giaccia AJ. Hypoxia, inflammation, and the tumor microenvironment in metastatic disease. Cancer Metastasis Rev (2010) 29:285-93. doi:10.1007/s10555-010-9224-5

66. Kawaguchi F, Kawaguchi AT, Murayama C, Kamijo A, Haida M. Liposomeencapsulated hemoglobin improves tumor oxygenation as detected by nearinfrared spectroscopy in colon carcinoma in mice. Artif Organs (2017) 41: 327-35. doi:10.1111/aor.12825

67. Murayama C, Kawaguchi AT, Kamijo A, Naito K, Iwao K, Tsukamoto H, et al. Liposome-encapsulated hemoglobin enhances chemotherapy to suppress metastasis in mice. Artif Organs (2014) 38:656-61. doi:10.1111/aor.12354

68. Fix SM, Borden MA, Dayton PA. Therapeutic gas delivery via microbubbles and liposomes. J Control Release (2015) 209:139-49. doi:10.1016/j. jconrel.2015.04.027

69. Burkard ME, Van Liew HD. Oxygen transport to tissue by persistent bubbles: theory and simulations. J Appl Physiol (1994) 77:2874-8. doi:10.1152/jappl. 1994.77.6.2874

70. Van Liew HD, Burkard ME. Relationship of oxygen content to PO2 for stabilized bubbles in the circulation: theory. J Appl Physiol (1996) 81:500-8. doi:10.1152/jappl.1996.81.1.500

71. Tachibana K, Feril LB, Ikeda-Dantsuji Y. Sonodynamic therapy. Ultrasonics (2008) 48:253-9. doi:10.1016/j.ultras.2008.02.003

72. Cavalli R, Bisazza A, Giustetto P, Civra A, Lembo D, Trotta G, et al. Preparation and characterization of dextran nanobubbles for oxygen delivery. Int J Pharm (2009) 381:160-5. doi:10.1016/j.ijpharm.2009.07.010

73. Cavalli R, Bisazza A, Rolfo A, Balbis S, Madonnaripa D, Caniggia I, et al. Ultrasound-mediated oxygen delivery from chitosan nanobubbles. Int J Pharm (2009) 378:215-7. doi:10.1016/j.ijpharm.2009.05.058 
74. Swanson EJ, Borden MA. Injectable oxygen delivery based on protein-shelled microbubbles. Nano Life (2010) 1:215-8. doi:10.1142/S1793984410000195

75. Swanson EJ, Mohan V, Kheir J, Borden MA. Phospholipid-stabilized microbubble foam for injectable oxygen delivery. Langmuir (2010) 26:15726-9. doi:10.1021/la1029432

76. Trendowski M. The promise of sonodynamic therapy. Cancer Metastasis Rev (2014) 33:143-60. doi:10.1007/s10555-013-9461-5

77. Mcewan C, Owen J, Stride E, Fowley C, Nesbitt H, Cochrane D, et al. Oxygen carrying microbubbles for enhanced sonodynamic therapy of hypoxic tumours. J Control Release (2015) 203:51-6. doi:10.1016/j.jconrel.2015.02.004

78. Mcewan C, Kamila S, Owen J, Nesbitt H, Callan B, Borden M, et al. Combined sonodynamic and antimetabolite therapy for the improved treatment of pancreatic cancer using oxygen loaded microbubbles as a delivery vehicle. Biomaterials (2016) 80:20-32. doi:10.1016/j.biomaterials.2015.11.033

79. Wigerup C, Pahlman S, Bexell D. Therapeutic targeting of hypoxia and hypoxia-inducible factors in cancer. Pharmacol Ther (2016) 164:152-69. doi:10.1016/j.pharmthera.2016.04.009

80. Kalluri R, Weinberg RA. The basics of epithelial-mesenchymal transition. J Clin Invest (2009) 119:1420-8. doi:10.1172/JCI39104

81. Mani SA, Guo W, Liao MJ, Eaton EN, Ayyanan A, Zhou AY, et al. The epithelial-mesenchymal transition generates cells with properties of stem cells. Cell (2008) 133:704-15. doi:10.1016/j.cell.2008.03.027

82. Gjerdrum C, Tiron C, Hoiby T, Stefansson I, Haugen H, Sandal T, et al. Axl is an essential epithelial-to-mesenchymal transition-induced regulator of breast cancer metastasis and patient survival. Proc Natl Acad Sci U S A (2010) 107:1124-9. doi:10.1073/pnas.0909333107

83. Yamada S, Fuchs BC, Fujii T, Shimoyama Y, Sugimoto H, Nomoto S, et al. Epithelial-to-mesenchymal transition predicts prognosis of pancreatic cancer. Surgery (2013) 154:946-54. doi:10.1016/j.surg.2013.05.004

84. Yamada S, Okumura N, Wei L, Fuchs BC, Fujii T, Sugimoto H, et al. Epithelial to mesenchymal transition is associated with shorter disease-free survival in hepatocellular carcinoma. Ann Surg Oncol (2014) 21:3882-90. doi:10.1245/ s10434-014-3779-2

85. Murai T, Yamada S, Fuchs BC, Fujii T, Nakayama G, Sugimoto H, et al. Epithelial-to-mesenchymal transition predicts prognosis in clinical gastric cancer. J Surg Oncol (2014) 109:684-9. doi:10.1002/jso.23564

86. Ye Z, Zhang X, Luo Y, Li S, Huang L, Li Z, et al. Prognostic values of vimentin expression and its clinicopathological significance in non-small cell lung cancer: a meta-analysis of observational studies with 4118 cases. PLoS One (2016) 11:e0163162. doi:10.1371/journal.pone.0163162

87. Brabletz T, Kalluri R, Nieto MA, Weinberg RA. EMT in cancer. Nat Rev Cancer (2018) 18:128-34. doi:10.1038/nrc.2017.118

88. Davis FM, Stewart TA, Thompson EW, Monteith GR. Targeting EMT in cancer: opportunities for pharmacological intervention. Trends Pharmacol Sci (2014) 35:479-88. doi:10.1016/j.tips.2014.06.006

89. Gupta PB, Onder TT, Jiang G, Tao K, Kuperwasser C, Weinberg RA, et al. Identification of selective inhibitors of cancer stem cells by high-throughput screening. Cell (2009) 138:645-59. doi:10.1016/j.cell.2009.06.034

90. Pattabiraman DR, Bierie B, Kober KI, Thiru P, Krall JA, Zill C, et al. Activation of PKA leads to mesenchymal-to-epithelial transition and loss of tumorinitiating ability. Science (2016) 351:aad3680. doi:10.1126/science.aad3680

91. Burkhalter RJ, Westfall SD, Liu Y, Stack MS. Lysophosphatidic acid initiates epithelial to mesenchymal transition and induces beta-catenin-mediated transcription in epithelial ovarian carcinoma. J Biol Chem (2015) 290: 22143-54. doi:10.1074/jbc.M115.641092

92. Liu S, Umezu-Goto M, Murph M, Lu Y, Liu W, Zhang F, et al. Expression of autotaxin and lysophosphatidic acid receptors increases mammary tumorigenesis, invasion, and metastases. Cancer Cell (2009) 15:539-50. doi:10.1016/j.ccr.2009.03.027

93. Tang X, Benesch MG, Dewald J, Zhao YY, Patwardhan N, Santos WL, et al. Lipid phosphate phosphatase-1 expression in cancer cells attenuates tumor growth and metastasis in mice. J Lipid Res (2014) 55:2389-400. doi:10.1194/ jlr.M053462

94. Banerjee S, Norman DD, Lee SC, Parrill AL, Pham TC, Baker DL, et al. Highly potent non-carboxylic acid autotaxin inhibitors reduce melanoma metastasis and chemotherapeutic resistance of breast cancer stem cells. J Med Chem (2017) 60:1309-24. doi:10.1021/acs.jmedchem.6b01270

95. Lee SC, Fujiwara Y, Liu J, Yue J, Shimizu Y, Norman DD, et al. Autotaxin and LPA 1 and LPA5 receptors exert disparate functions in tumor cells versus the host tissue microenvironment in melanoma invasion and metastasis. Mol Cancer Res (2015) 13:174-85. doi:10.1158/1541-7786. MCR-14-0263

96. Tager AM, Lacamera P, Shea BS, Campanella GS, Selman M, Zhao Z, et al. The lysophosphatidic acid receptor LPA1 links pulmonary fibrosis to lung injury by mediating fibroblast recruitment and vascular leak. Nat Med (2008) 14:45-54. doi:10.1038/nm1685

97. Pradere JP, Klein J, Gres S, Guigne C, Neau E, Valet P, et al. LPA1 receptor activation promotes renal interstitial fibrosis. J Am Soc Nephrol (2007) 18: 3110-8. doi:10.1681/ASN.2007020196

98. Nakagawa S, Wei L, Song WM, Higashi T, Ghoshal S, Kim RS, et al. Molecular liver cancer prevention in cirrhosis by organ transcriptome analysis and lysophosphatidic acid pathway inhibition. Cancer Cell (2016) 30:879-90. doi:10.1016/j.ccell.2016.11.004

99. Azuma H, Takahara S, Ichimaru N, Wang JD, Itoh Y, Otsuki Y, et al. Marked prevention of tumor growth and metastasis by a novel immunosuppressive agent, FTY720, in mouse breast cancer models. Cancer Res (2002) 62:1410-9.

100. Nagahashi M, Yamada A, Katsuta E, Aoyagi T, Huang WC, Terracina KP, et al. Targeting the SphK1/S1P/S1PR1 axis that links obesity, chronic inflammation, and breast cancer metastasis. Cancer Res (2018) 78:1713-25. doi:10.1158/ 0008-5472.CAN-17-1423

101. Lee TK, Man K, Ho JW, Wang XH, Poon RT, Xu Y, et al. FTY720: a promising agent for treatment of metastatic hepatocellular carcinoma. Clin Cancer Res (2005) 11:8458-66. doi:10.1158/1078-0432.CCR-05-0447

102. Li CX, Shao Y, Ng KT, Liu XB, Ling CC, Ma YY, et al. FTY720 suppresses liver tumor metastasis by reducing the population of circulating endothelial progenitor cells. PLoS One (2012) 7:e32380. doi:10.1371/journal. pone. 0032380

103. Lu Z, Wang J, Zheng T, Liang Y, Yin D, Song R, et al. FTY720 inhibits proliferation and epithelial-mesenchymal transition in cholangiocarcinoma by inactivating STAT3 signaling. BMC Cancer (2014) 14:783. doi:10.1186/ 1471-2407-14-783

104. van der Weyden L, Arends MJ, Campbell AD, Bald T, Wardle-Jones H, Griggs N, et al. Genome-wide in vivo screen identifies novel host regulators of metastatic colonization. Nature (2017) 541:233-6. doi:10.1038/ nature20792

105. Krzeszinski JY, Wan Y. New therapeutic targets for cancer bone metastasis. Trends Pharmacol Sci (2015) 36:360-73. doi:10.1016/j.tips.2015.04.006

106. Guise T. The vicious cycle of bone metastases. J Musculoskeletal Neuronal Interact (2002) 2:570-2.

107. Santini D, Vincenzi B, Avvisati G, Dicuonzo G, Battistoni F, Gavasci M, et al. Pamidronate induces modifications of circulating angiogenetic factors in cancer patients. Clin Cancer Res (2002) 8:1080-4.

108. Santini D, Vincenzi B, Dicuonzo G, Avvisati G, Massacesi C, Battistoni F, et al. Zoledronic acid induces significant and long-lasting modifications of circulating angiogenic factors in cancer patients. Clin Cancer Res (2003) 9:2893-7.

109. Vincenzi B, Santini D, Rocci L, Tonini G. Bisphosphonates: new antiangiogenic molecules in cancer treatment? Ann Oncol (2003) 14:806-7. doi:10.1093/annonc/mdg194

110. Santini D, Vincenzi B, Galluzzo S, Battistoni F, Rocci L, Venditti O, et al. Repeated intermittent low-dose therapy with zoledronic acid induces an early, sustained, and long-lasting decrease of peripheral vascular endothelial growth factor levels in cancer patients. Clin Cancer Res (2007) 13:4482-6. doi:10.1158/1078-0432.CCR-07-0551

111. Wu S, Dahut WL, Gulley JL. The use of bisphosphonates in cancer patients. Acta Oncol (2007) 46:581-91. doi:10.1080/02841860701233435

112. Misso G, Porru M, Stoppacciaro A, Castellano M, De Cicco F, Leonetti C, et al. Evaluation of the in vitro and in vivo antiangiogenic effects of denosumab and zoledronic acid. Cancer Biol Ther (2012) 13:1491-500. doi:10.4161/ cbt. 22274

113. Li BT, Wong MH, Pavlakis N. Treatment and prevention of bone metastases from breast cancer: a comprehensive review of evidence for clinical practice. J Clin Med (2014) 3:1-24. doi:10.3390/jcm3010001

114. Drooger JC, Van Der Padt A, Sleijfer S, Jager A. Denosumab in breast cancer treatment.EurJ Pharmacol(2013) 717:12-9. doi:10.1016/j.ejphar.2013.03.034

115. Fizazi K, Carducci M, Smith M, Damiao R, Brown J, Karsh L, et al. Denosumab versus zoledronic acid for treatment of bone metastases in men with 
castration-resistant prostate cancer: a randomised, double-blind study. Lancet (2011) 377:813-22. doi:10.1016/S0140-6736(10)62344-6

116. Gdowski AS, Ranjan A, Vishwanatha JK. Current concepts in bone metastasis, contemporary therapeutic strategies and ongoing clinical trials. J Exp Clin Cancer Res (2017) 36:108. doi:10.1186/s13046-017-0578-1

117. Alsaab HO, Sau S, Alzhrani R, Tatiparti K, Bhise K, Kashaw SK, et al. PD-1 and PD-L1 checkpoint signaling inhibition for cancer immunotherapy: mechanism, combinations, and clinical outcome. Front Pharmacol (2017) 8:561. doi:10.3389/fphar.2017.00561

118. Farkona S, Diamandis EP, Blasutig IM. Cancer immunotherapy: the beginning of the end of cancer? BMC Med (2016) 14:73. doi:10.1186/s12916-016-0623-5

119. Hodi FS, O’day SJ, Mcdermott DF, Weber RW, Sosman JA, Haanen JB, et al. Improved survival with ipilimumab in patients with metastatic melanoma. N Engl J Med (2010) 363:711-23. doi:10.1056/NEJMoa1003466

120. Robert C, Thomas L, Bondarenko I, O’day S, Weber J, Garbe C, et al. Ipilimumab plus dacarbazine for previously untreated metastatic melanoma. N Engl J Med (2011) 364:2517-26. doi:10.1056/NEJMoa1104621

121. Sharma P, Allison JP. Immune checkpoint targeting in cancer therapy: toward combination strategies with curative potential. Cell (2015) 161:205-14. doi:10.1016/j.cell.2015.03.030

122. Waterhouse P, Penninger JM, Timms E, Wakeham A, Shahinian A, Lee KP, et al. Lymphoproliferative disorders with early lethality in mice deficient in Ctla-4. Science (1995) 270:985-8. doi:10.1126/science.270.5238.985

123. Mellman I, Coukos G, Dranoff G. Cancer immunotherapy comes of age. Nature (2011) 480:480-9. doi:10.1038/nature10673

124. Chen DS, Mellman I. Oncology meets immunology: the cancer-immunity cycle. Immunity (2013) 39:1-10. doi:10.1016/j.immuni.2013.07.012

125. TopalianSL,SznolM,McdermottDF, KlugerHM,CarvajalRD, Sharfman WH, et al. Survival, durable tumor remission, and long-term safety in patients with advanced melanoma receiving nivolumab. J Clin Oncol (2014) 32: 1020-30. doi:10.1200/JCO.2013.53.0105

126. Ascierto PA, Vanella V, Grimaldi AM, Lucia F, Palla M, Simeone E, et al. Complete response to nivolumab monotherapy in a treatment-naive, BRAF wild-type patient with advanced mucosal melanoma and elevated lactate dehydrogenase: a case report from a phase III trial. Cancer Immunol Immunother (2016) 65:1395-400. doi:10.1007/s00262-016$1898-2$

127. Weinstein IB. Addiction to oncogenes - the Achilles heal of cancer. Science (2002) 297:63-4. doi:10.1126/science.1073096
128. Nelson DA, Tan T-T, Rabson AB, Anderson D, Degenhardt K, White E. Hypoxia and defective apoptosis drive genomic instability and tumorigenesis. Genes Dev (2004) 18:2095-107. doi:10.1101/gad.1204904

129. Stephens PJ, Tarpey PS, Davies H, Van Loo P, Greenman C, Wedge DC, et al. The landscape of cancer genes and mutational processes in breast cancer. Nature (2012) 486:400. doi:10.1038/nature11017

130. Ma L, Teruya-Feldstein J, Weinberg RA. Tumour invasion and metastasis initiated by microRNA-10b in breast cancer. Nature (2007) 449:682. doi:10.1038/nature06174

131. Moriarty CH, Pursell B, Mercurio AM. miR-10b targets Tiam1: implications for Rac activation and carcinoma migration. J Biol Chem (2010) 285:20541-6. doi:10.1074/jbc.M110.121012

132. Guessous F, Alvarado-Velez M, Marcinkiewicz L, Zhang Y, Kim J, Heister S, et al. Oncogenic effects of miR-10b in glioblastoma stem cells. J Neurooncol (2013) 112:153-63. doi:10.1007/s11060-013-1047-0

133. Yigit M, Ghosh S, Kumar M, Petkova V, Kavishwar A, Moore A, et al. Contextdependent differences in miR-10b breast oncogenesis can be targeted for the prevention and arrest of lymph node metastasis. Oncogene (2013) 32:1530. doi:10.1038/onc.2012.173

134. Yoo B, Kavishwar A, Ross A, Wang P, Tabassum DP, Polyak K, et al. Combining miR-10b-targeted nanotherapy with low-dose doxorubicin elicits durable regressions of metastatic breast cancer. Cancer Res (2015) 75:4407-15. doi:10.1158/0008-5472.CAN-15-0888

135. Yoo B, Kavishwar A, Wang P, Ross A, Pantazopoulos P, Dudley M, et al. Therapy targeted to the metastatic niche is effective in a model of stage IV breast cancer. Sci Rep (2017) 7. doi:10.1038/srep45060

Conflict of Interest Statement: ZM is a Founder, Director, and Scientific Advisory Board Member of TransCode Therapeutics, Inc. The other authors declare that the research was conducted in the absence of any commercial or financial relationships that could be construed as a potential conflict of interest.

Copyright (c) 2018 Yoo, Fuchs and Medarova. This is an open-access article distributed under the terms of the Creative Commons Attribution License (CC BY). The use, distribution or reproduction in other forums is permitted, provided the original author(s) and the copyright owner(s) are credited and that the original publication in this journal is cited, in accordance with accepted academic practice. No use, distribution or reproduction is permitted which does not comply with these terms. 